\title{
A Research on OBE-CDIO Finance Education Reform Under the Age of Big Data
}

\author{
Minghong Sun \\ Department of Information Management \\ Dalian Neusoft University of Information \\ Dalian, China \\ sunminghong@neusoft.edu.cn
}

\begin{abstract}
The age of big data changes the performances of the whole industries, so as the financial talent education. This article aims to establish the new financial talent cultivation model based on CDIO engineering conceive and OBE conceive in order to better train the financial talents in the new world of big data. First, the paper investigated the impacts of big data on financial industry and the transformation of financial talents that the new society needs. Then, we clearly described how our model worked, that thoroughly integrated big data into the engineering education conceive from talents' grade one to grade four. Last, we gave some suggestions and hope this new OBE-CDIO finance education model with big data will be helpful to cultivate the senior composite financial talents who are application-oriented, informatization, and can extract as well as analyze the big data to create value for the society.
\end{abstract}

Keywords-finance education; big data; CDIO; OBE

\section{INTRODUCTION}

With the arrival of 'cloud' era, the word, 'big data', is frequently mentioned nowadays. All industries have been a clearly consensus that big data will be the next center of competition strategy. During the 19th National Congress of the Communist Party of China, President Xi Jinping specially emphasized in the economic report, that the real economy's future development of China should be thoroughly integrated Internet, Big Data, and Artificial Intelligence. Thus, it can be predicted that the effect of the big data will continuously and in-depth reform the Chinese economy system. The innovation of the industries inevitably reforms the education fields. As the front to convey the talents to the industry, universities not only should train the talents with this new big-data technique, but also should update our talent cultivation models and take fully advantage of big data into the model. In this article, after investigating the impact of big data on financial industry, an innovative financial engineering talents training model was designed which big data is introduced in CDIO-OBE talents training system, and hope to give some suggestions to cultivate the senior composite financial talents who are applicationoriented, informatization, and can extract as well as analyze the big data under the new age.

\section{THE SHOCKS OF BIG DATA IN FINANCE INDUSTRY}

'Big Data' is early put forwarded by McKinsey Global Institute (2011), their report 'the Big data: The next frontier for innovation, competition, and productivity' suggested that big data is the extraordinarily large data sets whose amount of data has been exploding, and analyzing [1]. International Data Company (IDC) defined big data with four dominants: 1) first, volume. The report showed that in 2011 the total amount of the data created and copied is 1.8ZB (the 70 power of 2) and forecasts that till 2020, the volume of data will be up to 35ZB; 2) Second, variety. Compared with the structural data stored in text form before, under the age of big data, most of the data are transformed into semi-structural and non-structural, saved as picture, video, audio, geographical location etc.; 3) third, value. The set of data has low value density. For example, a threehour continuous supervision, only $3 \sim 5$ seconds are valuable for detectors to solve a case. Thus exacting and analyzing effective data is the core problem of big data; 4) forth, velocity. To face such a vast amount of data, working efficiency is essential and processes required to be instantly conducted to make a timely response.

Finance industry as the important data producers and consumers, in this battle, cannot ignore the valuation of big data. Along with the maturity of internet technology and cloud computing, as the core assets of financial innovation, the accumulation of large data has been reforming the traditional customer relationship and the position of credit in finance services. On one hand, emerging finance industry, take Alipay as a significant representative, is crashing down the traditional financial institutions, market and trading mode. On the other hand, traditional financial institutions are actively responding to this battle, seen as Fig. 1.
Supported by the Project Number W2015048, the General Project of Education Humanities and Social Sciences in Liaoning Provincial Department of Education "Research on Operation Mode of Inclusive Financial system under the Age of Internet+". 


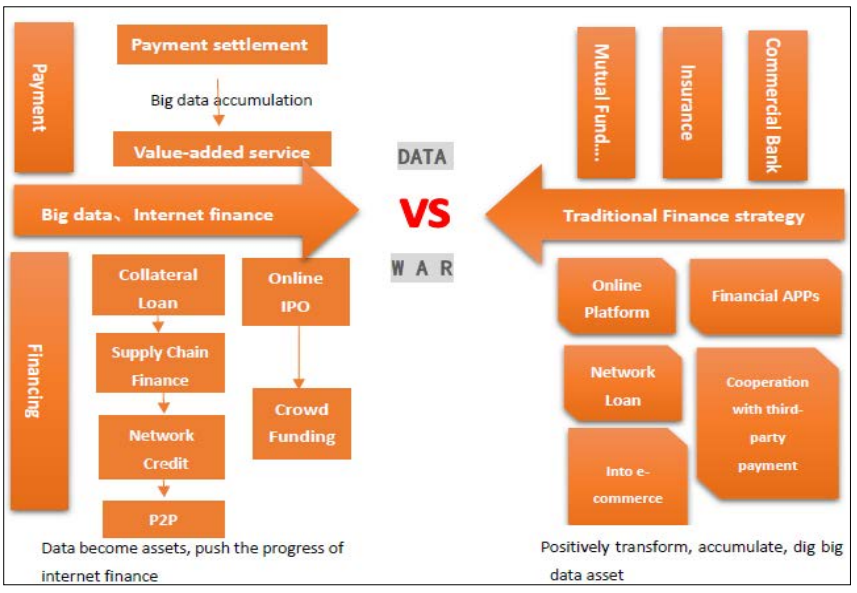

Fig. 1. Finance data war under the age of big data

\section{A. Emerging Finance Industry}

On one hand, daily payment system is changed by the financial innovations. Released on August, 2017, Chinese internet development statistic report found that as of June 2017, the habit of people who is used third-party payment to settle the receipts in the supermarket, stores and other offline stores has been deepening. The rate of offline shopping used by a thirdparty online payment reaches $61.6 \%$, as shown in Fig. 2 [2]. Moreover, the third-party platforms accumulate and take fully advantage of the clients' data to enlarge their value-added services, Ant Check Later of Alipay platform as an example.

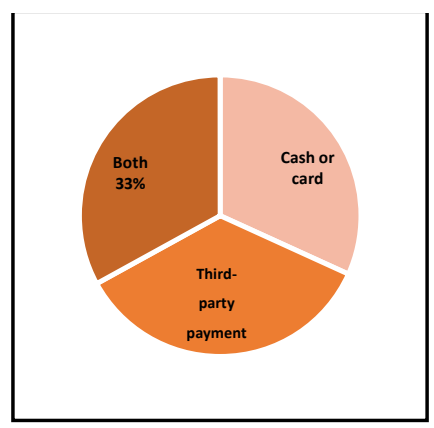

Fig. 2. Research on payment choices

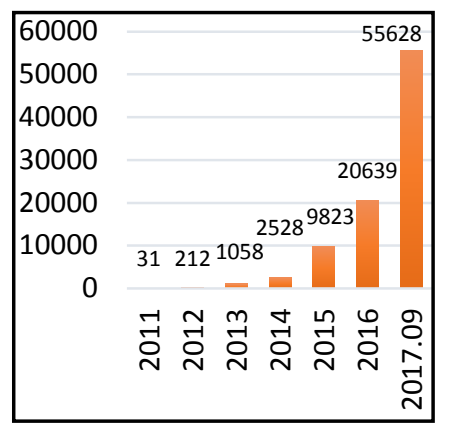

Fig. 3 P2P trading volume
On the other hand, the ways of financing become more flexible and efficient. For debt financing, data accumulation promotes the supply chain finance instead of the traditional collateral loan, which makes better implementation of the security monitoring function. Then, as the development of internet finance, debt financing was secondly reformed towards the network credit. Now attractive by the high profitability and flexibility, investors and debtors show great interests in peer to peer lending (P2P). Seen in the Fig. 3, as of September 2017, the trading volume of $\mathrm{P} 2 \mathrm{P}$ arrived at 0.56 billion, $170 \%$ increased from 2016. For equity financing, the tendency has been towards crowd funding from the online IPO. As of July 2017, the number of crowd funding platforms is up to 203 and the accumulated amount of financing is $\mathbf{5 5 0 0}$ million Yuan.

\section{B. Responses from Traditional Financial Institutions}

In the face of such situations, traditional financial institutions such as banks, insurance and mutual funds has been actively changing their operation modes with big data and internet finance. Traditional financial institutions themselves have already accumulated massive data of their customers, but on the foundation of the big data integration, they can innovate new channels and methods to obtain more data. Financial apps, online platforms are quickly established, as well, institutions carry out cooperation with e-commerce platforms, such as Alipay platform, to grant the rapid small payments. In addition, taking advantages of WeChat and Weibo social platforms, traditional institutions launched the innovative propaganda work, which creates the new opportunities of financial informatization development by integration the external customer data with the bank business data based on internet finance and big data techniques.

In the era of big data, customer data gradually transforms from the traditional decentralized processing to systematic encapsulation. The core competence of big data is the analysis ability of the mass of multi-type data processing. The internet's powerful data collection ability grifts the big data to traditional financial industry. Big financial data has been becoming the new drive center to shape up the true 'Blue Ocean' which takes the customers as the service center [3].

\section{THE DEMAND OF FINANCIAL TALENTS UNDER BIG DATA}

\section{A. Rapid Growth of Financial Talents Demand}

With the innovation and revolution of Chinese finance, large numbers of domestic and international financial business has occurred, which leads to the market need more financial talents. Since 2014, the demand for financial talents has been in a state of blowout according to the reports by finance ying.com and zhaopin.com. The survey also showed that there is a large financial talent gaps in Shanghai, Beijing, Guangdong and Jiangsu provinces. Talents demand in the financial sector rose 15.8 percent in June of 2017, compared with the same period a year earlier according to the latest recruitment data from the ying.com. In terms of positions, third-party payment product managers, internet financial product managers and financial product sales managers showed the strong demands trend, which recruitment demands rose by $16.7 \%, 15 \%$ respectively also compared with the same period last year. Therefore, under this talents shortage situation, universities burden the important task to convey the qualified talents to the financial industry.

\section{B. Composite Application Talents Demand}

With the acceleration of RMB internationalization progress, cross investment opportunities between foreign financial institutions and domestic ones are increasing and push the market to ask higher requirements for financial personnel's comprehensive abilities. In addition, due to the emerging features of new finance, that is, more labor specialization, the increasing financial innovative instruments, internet finance mode, big data techniques, and so on, high levels of informatization skills, foreign language skills, and the abilities of innovative thinking and flexibility are needed for the current senior composite financial talents. 


\section{Financial Certification Demanded for Talents}

At present, the domestic financial market is in urgent need of the financial analysts with some certificates, such as charted financial analyst (CFA), financial risk manager, chartered wealth manager, fund managers, actuaries, etc. In particular, the senior talents who are charge of financial risk control are well in demand since the high risk of internet control. As of 2016, the talents who hold the financial risk management certificate FRM are no more than 4000 people in Chinese region.

The innovation and reform of the finance industry bring new opportunities and challenges to the cultivation and management of financial talents. Universities should quickly respond to the new state of the financial market, reconsider the finance curriculum system as well as talent cultivation plan, and accelerate the reform of curriculum system and training to meet the applicable, informatizational needs of the composite talents under the age of internet finance and big data.

\section{OBE-CDIO BASED FINANCE EDUCATION REFORM}

The changed demand makes current financial talents need refined division of labor, higher level of profession and composite vocational ability, which suggests that students in the campus should arm with the comprehensive academic quality and market-oriented operability. In addition, under the big data age it is necessary to take fully advantage of the data collection and analysis to form the talents cultivation model. The model should strengthen the industry-teaching-researching curriculum system, stress on the projects-based education and train the ordered talented based on the university-institutes cooperation to realize the seamless docking from school to work. Meanwhile, all the cultivation data is imported to the database, casebase and so on, analyzing and updating the talent model timely. Thus, this paper discusses the reform of education training model for financial talents by the OBECDIO engineering concept by fully used big data technique.

CDIO is one of the most famous engineering education reform conceive in recent years. Established in 2004, four famous universities like the Massachusetts institute of technology (MIT), the Swedish royal Institute of technology etc. constitute the international collaborative committee named after CDIO. CDIO conceive represents Conceive-DesignImplement-Operate comprehensive value-added engineering education systems. It is highly summarized and expressed the concept of 'learning by doing' and 'project -based education and learning'. It also embodies the basic abilities that modern engineers should conduct the working process beginning from conception, to design, to implement lastly [4]. These abilities include not only professional skills, but also personal and interpersonal ones, such as communication and creativity in the process [5]. Furthermore, CDIO conceive specifically design the systematic ability training scheme, implementation process and the evaluation standard of article 12, which makes the education reform have strong maneuverability.

OBE, outcome-based education is an education theory, which aims to make each part of educational activities around education goals (outcomes). It is a student-centered learning philosophy that focuses on empirically measuring student performance, which is called outcomes. There is no single specified style of teaching or assessment in OBE; instead, classes, opportunities, and assessments should all help students achieve the specified outcomes [6]. Thus, the role of the faculty adapts into instructor, trainer, and/or mentor based on the outcomes targeted, such as certification achievements.

After having a thorough study of OBE and CDIO conceive, we established our own finance talent education system, which is called OBE-CDIO Finance Education Reform. It integrated outcome-based education applied into the CDIO engineer conceives. OBE assist the CDIO training system with a clearly target, while, the CDIO system designs the detail education procedures to realize OBE, which plays the mutual promotion effects on each other. Market's demand, as the one of the core outcomes, is extracted and subdivided into the ConceiveDesign-Implement-Operating training system. CDIO initiative is mapped to our curriculum system, specific in each course, topic, project and innovative practical activity [7]. The progressive financial talents' training model is built for undergraduates through four year's study, which is horizontally integrated with the industrial practical training resources both inside and outside campus, synchronously, combined with the vertical industrial-research-teaching, which constitutes a triple helix interacted talent training, seen as Fig. 4.

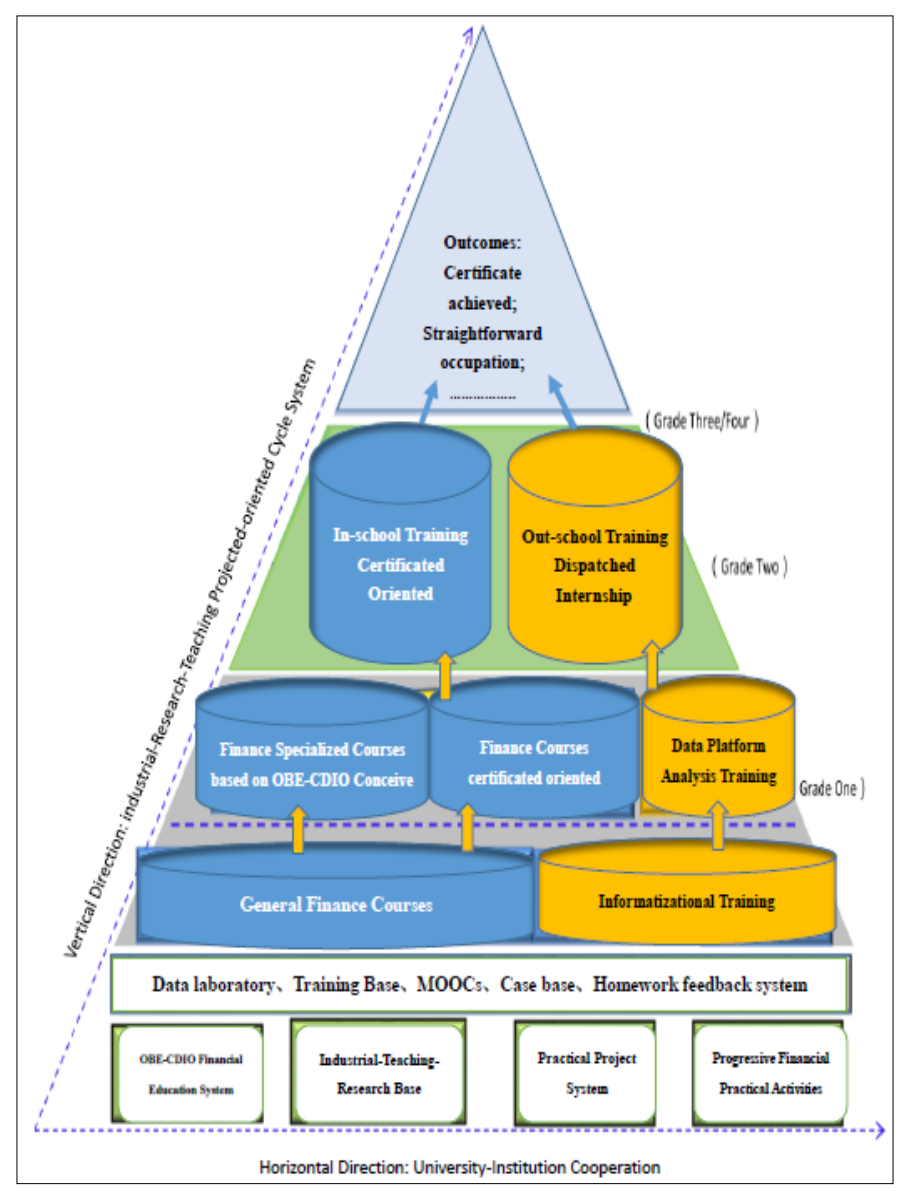

Fig. 4. OBE-CDIO based finance education reform model 


\section{A. Finance education reform target and establish ' $1+3+2+1$ ' learning system}

Finance education reform is mainly to cultivate practical and informatizational composite talents to face the big data age. We cultivate the students who not only should lay the solid foundation on the financial academic knowledge, but also can be practical to extract and analyze the data to make the plan of the financing, investment decisions and provide financial informatizational service, etc. In order to realize our finance reform target, we establish ' $1+3+2+1$ ' learning system. That is, ' 1 ' academic year is divided into ' 3 'semesters, ' 2 ' theoretical semester and ' 1 ' practical semester. A progressive and pluralistic training curriculum is designed to experience the real working environment, like, case study in normal theory course - enterprise simulation project in the practical semester. Till the third and fourth-year, based on students' outcome evaluation, student is instructed to achieve related certifications by the in-school training or participate in authentic training as dispatched internship in the collaborative corporates. Every student has his own profile imported in the database, and after assembling data, feedback, evaluates and adjust the model. On the other side, the application of financial software (Wind, SAP HANA, specially design for big data) is trained in the practical semester to make the students quickly adjust themselves to the real working position after graduation.

\section{B. Horizontally integrated the industrial practical training resources and environment both inside and outside school}

Education cannot be oriented away from social productive labor and social practice, which is the only way to promote human development [7]. So the Academic education must keep good communication and interaction with the industry to make students conform to the needs of industrial development. It is known that the production problems arouse the research topic, while the academic achievements on the contrary will be applied to the industrial productions. In the construction of OBE-CDIO Finance education reform system, a large number of enterprises elements are directly involved in our finance education reform which is horizontally integrated the industrial practical training resources and environments both inside and outside campus synchronously. Practical training base, real corporate programs, casebase, and flexible learning system MOOCs, are taken as an examples for universityenterprise jointly to improve the reform of financial education.

\section{Vertically establish the industrial-research-teaching triple helix interacted system}

In the vertical direction, the reform model is combined the academic teaching and research with the modern latest industrial production, which builds as triple helix interaction system. Thus the teaching will be assisted by the research, and moreover, academic achievements can apply to the industrial production, which finally forms a unique practical productionresearching-teaching progressive model. To specific, we establish close relationships with enterprises and invite the skilled experts who as an example are knowledgeable of big finance data or internet finance with industrial and academic backgrounds to exchange the ideas with students. Besides, teachers are encouraged to be assigned to the enterprise for a while, which cultivates teachers' awareness of finance cuttingedge. It helps the scientific and technological achievements to be transferred to the market.

\section{CONCLUSION}

Senior composite talents are one of the core elements for the development of current financial market. Cultivating talents with strong comprehensive analysis ability can not only improve the efficiency of work, also creates inestimable value for the enterprise. However, nowadays college students have the problem on lack of this ability, so it is necessary for universities to reform finance education to the cultivation of composite talents nowadays. The OBE-CDIO conceive finance education reform model is one of the solution to this problem, by melting programmatic engineering concept and practical ability into the university four years' education. Under the background of big data integration, OBE-CDIO model as the basic framework strengthens the students' practical ability, team spirit, informatization and comprehensive analytical ability. Centered on the students, scientific courses, projects and practical training are set by the outcomes, which of the target is clearly to work hard. Through the unremitting efforts to do the practical exploration and implementation, OBE-CDIO finance education reform model will be able to cultivate undergraduates to become innovative and outstanding financial professors to well adapt the new business world.

\section{ACKNOWLEDGMENT}

Thanks to the Project Number W2015048, the General Project of Education Humanities and Social Sciences in Liaoning Provincial Department of Education "Research on Operation Mode of Inclusive Financial system under the Age of Internet+".

\section{REFERENCES}

[1] [MGI and McKinsey. 'the Big data: The next frontier for innovation, competition, and productivity, Mc Kinsey Global Institute, 2011

[2] CNNIC. Chinese internet development statistic report. http://news.ifeng.com/a/20170804/515650510.shtml, 2017. In Chinese

[3] Jiang, Shuyang. A research on valuation innovation of internet finance under the background of big data, market modernization 2014 vol.20,pp203-204. In Chinese

[4] E.F.Crawley. Creating the CDIO Syllabus, a universal template for engineering education, fie, vol.3, pp.F3F8 -13, 32nd Annual Frontiers in Education(FIE’02), 2002.

[5] Massachusetts Institute of Technology School of Engineering Committee on Engineering Committee on University undergraduate Education, Eight Goals of an Undergraduate Education, Cambridge, MA,1998.

[6] Spady,William. Outcome-Based Education: Critical Isues and Answers ArlingtonVirginia: American Association of School Administrators. Retrieved, 2014.

[7] Jiang Xiaoluo,Li Han. CDIO-based Embedded Systems Training Mode in Graduate Teaching, 2011 5th International Conference on Distance Learning and Education, 2011, pp.73-77 